\title{
The updated Sydney system: Classification and grading of gastritis as the basis of diagnosis and treatment
}

\author{
Manfred Stolte $\mathrm{MD}^{1}$, Alexander Meining $\mathrm{MD}^{2}$
}

M Stolte, A Meining. The updated Sydney system: Classification and grading of gastritis as the basis of diagnosis and treatment. Can J Gastroenterol 2001;15(9):591-598. In recent years, the importance of the histological diagnosis of gastritis on the basis of routinely obtained antral and corpus biopsies has increased enormously, which is owed not least of all to the discovery of Helicobacter pylori. The introduction of the Sydney system made it possible, for the first time, to grade histological parameters, identify topographical distribution and, finally, make a statement about the etiopathogenesis of the gastritis. Of pathogenetic importance is, in the first instance, the differentiation between gastritis with and gastritis without $H$ pylori infection. The group of $H$ pylori-associated gastritis can be further subdivided into forms of gastritis whose morphological distribution patterns usually identify them as sequelae of $\mathrm{H}$ pylori infection, while the group of gastritis unassociated with $\mathrm{H}$ pylori can be differentiated into autoimmune, chemically induced reactive gastritis, ex-H pylori gastritis, Helicobacter heilmannii gastritis, Crohn's gastritis and a number of special forms of gastritis.

Key Words: Autoimmune gastritis; Crohn's disease; Gastritis; Helicobacter pylori

\section{Mise à jour du système de Sydney : la classification et la typologie de la gastrite sont les éléments clés du diagnostic et du traitement}

RÉSUMÉ : Au cours des dernières années, le diagnostic histologique de la gastrite à partir de biopsies systématiques du corps et de l'antre de l'estomac a gagné énormément d'importance, ce qui a conduit à la découverte, entre autres et non pas la moindre, d'Helicobacter pylori. La mise en place du système de Sydney a permis, pour la première fois, de définir des paramètres histologiques, de déterminer la répartition topographique et, finalement, de se prononcer sur l'étiopathogenèse. Point digne de mention à ce dernier égard, il y a d'abord la différence entre la gastrite associée à une infection à $H$. pylori et celle qui ne l'est pas. Ensuite, le groupe de gastrites associées à $H$. pylori peut se subdiviser davantage en forme de gastrites dont la répartition morphologique est généralement assimilée aux séquelles d'une infection à $H$. pylori; quant au groupe de gastrites non associées à $H$. pylori, il peut se différencier en gastrite auto-immune, chimique, réactionnelle, en ex-gastrite à $H$. pylori, à Helicobacter heilmanii, de Crohn et en un certain nombre de formes particulières de gastrite.

\footnotetext{
${ }^{1}$ Department of Pathology, Klinikum Bayreuth, Bayreuth, Germany; ${ }^{2}$ Medical Department II, Klinikum rechts der Isar, Technical University of Munich, Munich, Germany

Correspondence and reprints: Dr M Stolte, Department of Pathology, Klinikum Bayreuth, Preuschwitzerstr 101, 95445 Bayreuth, Germany.

Telephone +49-921-400-5600, fax +49-921-400-5609, e-mail pathologie.klinikum@bnbt.de

Received for publication August 11, 1999. Accepted November 16, 1999
} 


\section{HISTORICAL BACKGROUND}

Until the 1980s, research into gastritis was sparse and not particularly attractive. There were many classifications that differed from one country to another, sometimes from one department to another and occasionally even within a single institution, depending on the investigator concerned. This somewhat chaotic situation made the comparison of the results of various scientific studies virtually impossible. For the most part, no therapeutic consequences were derived from the diagnosis of gastritis. Until the discovery of Helicobacter pylori (formerly Campylobacter pylori) by Warren and Marshall in 1983, gastritis was considered a more or less useful histological finding but not a disease (1). The need for a biopsy-based diagnostic workup was thus questioned until the late 1980s. In 1990, on the basis of the new etiological facts on gastritis that had been collected, a new system of classification finally was presented at the World Congress of Gastroenterology held in Sydney, Australia (2). This 'Sydney System' was based largely on previous proposals made in the United Kingdom (3) and Germany (4). The decisive feature of this new system was that, for the first time, it appeared to allow statements to be made on the etiology, topography and morphology of gastritis. The Sydney system was, however, not immediately accepted everywhere, and the criticism was voiced, particularly in the United States, that older 'entities' of gastritis such as diffuse antral gastritis and multifocal atrophic gastritis (MAG), for example, apparently no longer appeared in the classification (5). As a consequence of such criticisms, a compromised system, now known as the updated Sydney system, was worked out at the H pylori congress held in 1994 in Houston, United States.

\section{PRACTICAL CONSEQUENCES OF THE UPDATED SYDNEY SYSTEM}

Endoscopy carried out to investigate gastroenterological diseases should always include taking biopsy specimens. For this purpose, the original Sydney system considered two biopsies each from the antrum and corpus obtained during gastroscopy to be adequate (2), whereas in the updated Sydney system, an additional biopsy taken from the incisura angularis is recommended (6). This additional biopsy was believed to be necessary because of the notion that because "maximal degrees of atrophy and intestinal metaplasia are found in the region of the incisura angularis" (6), the sampling error associated with the detection of MAG could be kept to a minimum. Prospective studies aimed at establishing whether the incisura angularis biopsy actually does bring the expected advantage have, to our knowledge, not been carried out so far. The authors have performed such a study (unpublished data) and were unable to find any advantage provided by the additional angulus biopsy compared with that provided by the standard two antral and two corpus biopsies. For the accurate grading of the individual parameters to be investigated, namely grade and activity of gastritis, density of $\mathrm{H}$ pylori colonization, and degree of intestinal metaplasia and atrophy grading in accordance with the updated Sydney
System using the visual analogue scale proposed in that system, the reader is referred to the original publication (6). It is worth noting, however, that, even after the introduction of the visual analogue scale, the grading of atrophy continues to be associated with considerable interobserver variability, with a kappa value of less than 0.5 (7). Just as problematic is the grading of intestinal metaplasia, because the examination of only two biopsies each from the corpus and antrum, and a single biopsy from the angle is associated with a danger of sampling error. For example, the grade of metaplasia can be overestimated if the biopsy happens to reveal individual foci of intestinal metaplasia in a patient with otherwise metaplasia-free mucosa. Conversely, if, despite the presence of extensive metaplasia, the biopsy is obtained from normal neighbouring mucosa, the result is a false negative. In contrast, grading of the diffuse gastritis parameters - density of infiltration of the lamina propria with lymphocytes and plasma cells, and density of infiltration of the mucosa with neutrophils (activity) - is associated with good interobserver variability (unpublished data). Moreover, a point of particular importance is that the overall agreement on the etiopathogenetic diagnosis of gastritis is good to very good, thus making this diagnosis readily reproducible worldwide.

\section{NON-H PYLORI-ASSOCIATED FORMS OF GASTRITIS}

Before and after the publication of the two Sydney systems, the rediscovery of $H$ pylori led to a renaissance in the field of gastritis research. As a result, a number of forms of gastritis not directly related to the bacterium were newly discovered or more accurately defined.

Chemically induced/reactive gastritis: Endogenous or exogenous substances with toxic potential for the gastric mucosa are the causes of this form of gastritis. The first description of this type of gastritis was published by Sobala and co-workers (8), who described bile reflux gastritis in the operated stomach. The histological presentation of this gastritis is characterized by tortuous hyperplastic foveolae and apical fibrosis of the lamina propria, with hyperplasia of smooth muscles cells in the lamina propria. Parallel to this, there may be low grade chronic inflammatory infiltrations and intestinal metaplasia (Figure 1). In addition to the biliary reflux in the operated stomach, this pattern is often also found in association with the use of nonsteroidal antiinflammatory drugs (NSAIDs) (6). The chemically induced/reactive form of gastritis is, histologically, a relatively certain diagnosis. However, the following questions still need to be clarified: how often this gastritis occurs in biliary reflux or with NSAID use; whether different NSAID preparations, their dosage or their duration of use lead to differences in the severity of the gastritis; whether chemically induced/reactive $H$ pylori mixed gastritis exists; and whether the differential diagnosis of chemically induced/reactive gastritis and ex-H pylori gastritis after antibiotic treatment is possible. In the practical setting, after an endoscopy and biopsy in a patient with symptoms of dyspepsia, the diagnosis of chemically induced/reactive gastritis in patients with an 
uncertain history may be evidence of possible abuse of painkillers or duodenogastric reflux.

'Ex'-H pylori gastritis: Studies in which gastritis has been followed up over a lengthy period by endoscopy and biopsy after eradication of $\mathrm{H}$ pylori infection have been able to show that the neutrophil infiltrate disappeared completely, while infiltration of the mucosa with lymphocytes and plasma cells persisted, albeit only to a very slight degree. However, other parameters such as intestinal metaplasia or lymphoid follicles, which are often formed in association with $H$ pylori infection, may still be found in the mucosa several years after eradication of $H$ pylori $(9,10)$. These, together with other factors, occasionally make the differential diagnosis vis-a-vis chemically induced/reactive gastritis somewhat difficult. If, however, the patient's history reliably excludes a chemically toxic cause, the presence of low grade, inactive gastritis with lymphoid follicles raises the suspicion of intentional or unintentional (that is, as a side effect of antibiotic treatment for sinusitis, for example) eradication of $H$ pylori at some earlier point in time (Figure 2).

Helicobacter heilmannii gastritis: H heilmannii gastritis is a relatively rare form of gastritis, and the incidence of infection with H heilmannii in the material submitted to Stolte et al (11) was approximately $0.1 \%$. This bacterium has a corkscrewlike appearance and is two to three times as long as $\mathrm{H}$ pylori (12). On the basis of these morphological features, it can readily be detected in gastric biopsy specimens and distinguished from $\mathrm{H}$ pylori (Figure 3). Gastritis induced by $\mathrm{H}$ heilmannii is a much lower grade than that induced by $\mathrm{H}$ pylori. It leads to intestinal metaplasia or atrophy in very few cases (13). Epidemiological data, together with DNA fingerprint studies, point to domestic animals (pigs, dogs and cats) as the source of infection with H heilmannii gastritis $(14,15)$.

Gastritis in association with Crohn's disease: This form of gastritis is characterized not so much by accompanying visible changes in the stomach that are typical of Crohn's disease such as aphthae, ulcers, edematous mucosa, etc, as by the presence of certain features that are recognizable only histologically. In rare cases, these histological findings may be epithelioid cell granulomas $(16,17)$, but in the majority of all such cases, Crohn's gastritis is characterized by focal periglandular lymphocytic infiltrates (17-19) (Figures 4 and 5). This type of gastritis is found in roughly $60 \%$ to $70 \%$ of patients suffering from Crohn's disease; its positive predictive value for the histological diagnosis of Crohn's disease is $94 \%$, and its negative predictive value is $37 \%$. A concomitant $\mathrm{H}$ pylori gastritis is usually relatively rare $(17,19,20)$, but, under certain circumstances, Crohn's disease may be masked by the inflammatory infiltrate developing in response to infection with $H$ pylori and thus may be missed. In such cases, healing of the $H$ pylori gastritis may help to uncover the Crohn's gastritis (21). In a few rare cases, focal inflammatory infiltrates may also be a consequence of an acute infectious gastritis with an invasive organism. In contrast to Crohn's gastritis, however, mainly neutrophils are found in this type of infectious gastritis.
Granulomatous gastritis: When epithelioid cell granulomas with and without multinucleate giant cells are found, only a descriptive diagnosis is usually possible. Follow-up investigations in 250 consecutive patients that the authors diagnosed as having granulomatous gastritis revealed that, at least in Germany, this form of gastritis commonly $(60 \%)$ indicates the presence of Crohn's disease, while foreign body granulomas $(14 \%)$ and other granulomatous conditions with involvement of the gastric mucosa, such as Boeck's disease, tuberculosis and syphilis, are rarely found (together 7\%) (own unpublished data). In $19 \%$ of the cases, no triggering mechanism was identified (idiopathic granulomatous gastritis).

The recent perception that Crohn's disease is frequently accompanied by focal, discontinuous (patchy) gastritis has resulted in considerable improvement in the diagnosis of granulomatous gastritis. If, for example, a combination of focal Crohn's gastritis and epithelioid cell granulomas is present, such granulomas are, in all probability, associated with Crohn's disease (unpublished data).

Autoimmune gastritis: As the name implies, autoimmune gastritis is characterized by atrophy of the glands in the corpus mucosa caused by the cells of the body's own immune defence system. For the most part, two different forms of autoimmune gastritis can be differentiated - the 'active' form, which is characterized, in particular, by periglandular lymphocytic infiltration, with local destruction of corpus glands and hypertrophy of the parietal cells (Figures 6 and 7), and the 'burned out' form, which involves complete atrophy of the parietal cells, with only low grade chronic infiltrates persisting. Previously, it was believed that both forms were associated serologically with antibodies against parietal cells and/or intrinsic factors (22). However, this need not be the case, because the investigations carried out by Faller et al (23) and Negrini et al (24), for example, have shown that some of the antibodies developed against $H$ pylori may react with the proton pump of the parietal cell as antigens. H pylori thus stimulates the formation of autoimmune antibodies. Accordingly, an incipient 'active' autoimmune gastritis that is simultaneously associated with infection with $H$ pylori ought to be healed by simply eradicating the organism. Case reports, together with the current results of an ongoing pilot study the author and colleagues $(25,26)$ are carrying out, provide support for this hypothesis. In this exciting field of $\mathrm{H}$ pylori-induced autoimmune gastritis, however, numerous questions still remain to be answered; for example, it is not sufficiently well known which host factors and which bacterial factors are capable of triggering this autoimmunity, and why only some of the patients shown to have antigastric antibodies actually go on to develop autoimmune gastritis.

Special forms of gastritis: Classified under the special forms of gastritis are eosinophilic gastritis, lymphocytic gastritis, collagenous gastritis (Figure 8) as an additional manifestation in patients with collagenous colitis, and rare forms induced by infections with mycobacteria, Treponema pallidum, cytomegalovirus (Figure 9), measles viruses, parasites such as Stongyloides stercoralis or Anisakis marina, or fungi (Figure 10). 


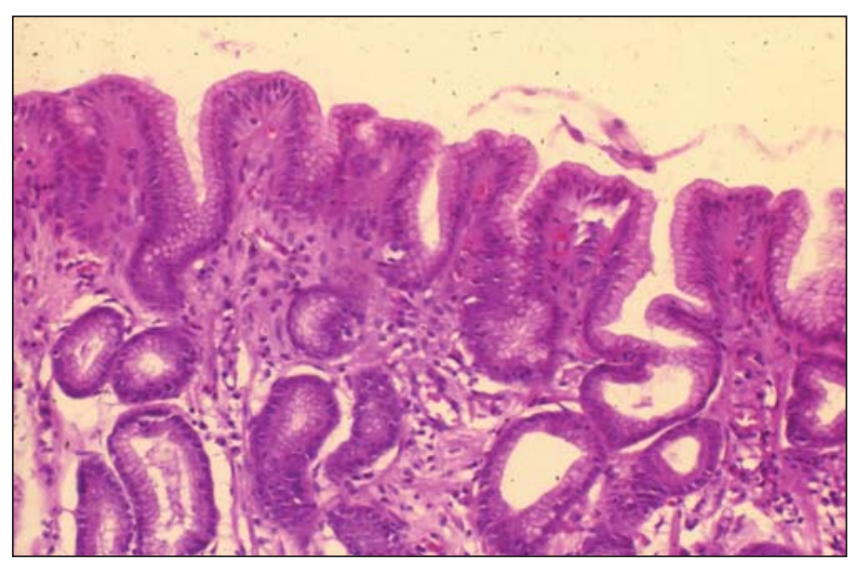

Figure 1) Chemically induced reactive gastritis of the antral mucosa with apical fibrosis, tortuous foveolae, hyperplasia of the smooth muscles in the lamina propria and minimal nonactive chronic inflammation
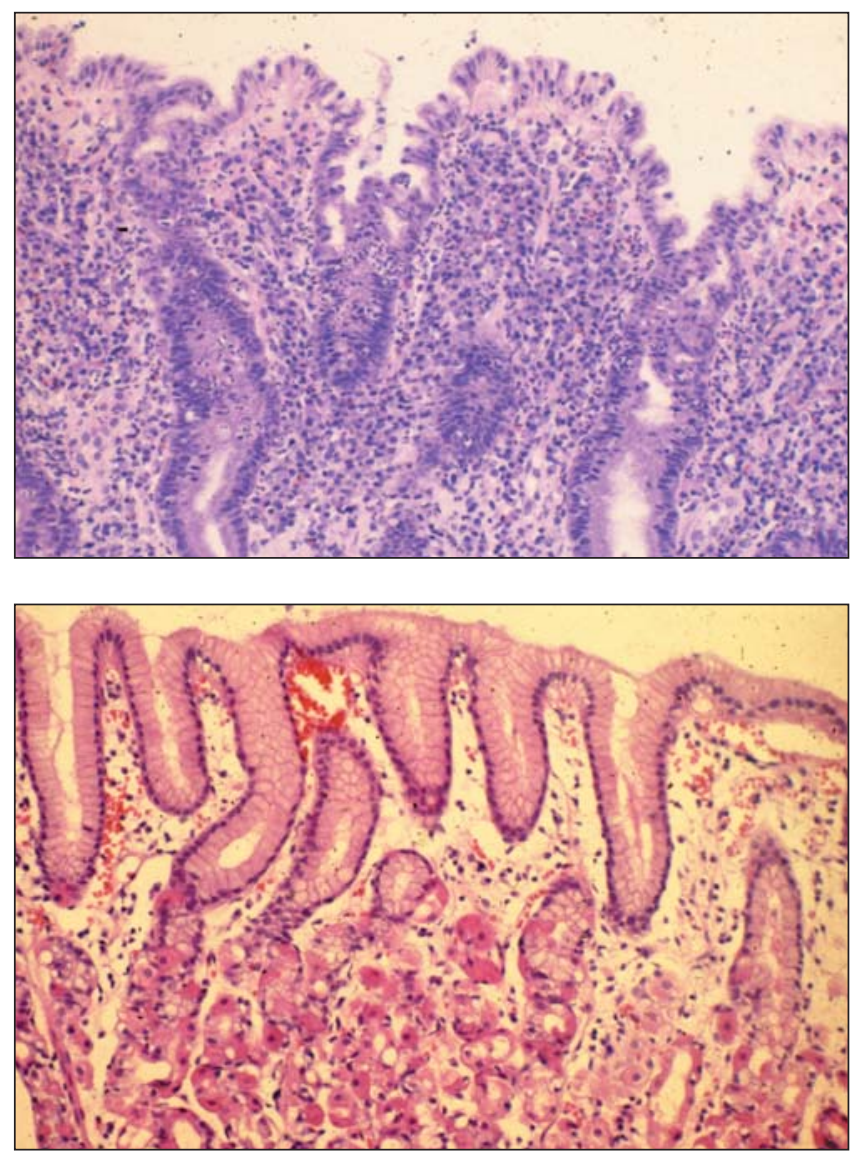

Figure 2) Severe, chronic active Helicobacter pylori gastritis with replacement of normal foveolar epithelium by regenerative epithelium and mucus depletion before (Top) and after $\mathrm{H}$ pylori eradication, with normalization of the surface epithelium and mucus production, and mild, nonactive chronic inflammation (Bottom)

The latter forms of gastritis, which are characterized by infection with opportunistic organisms or parasites, are rare findings. In immunosuppressed patients or HIV-infected subjects with dyspeptic symptoms, however, they may occur more frequently and should, therefore, not be left out of

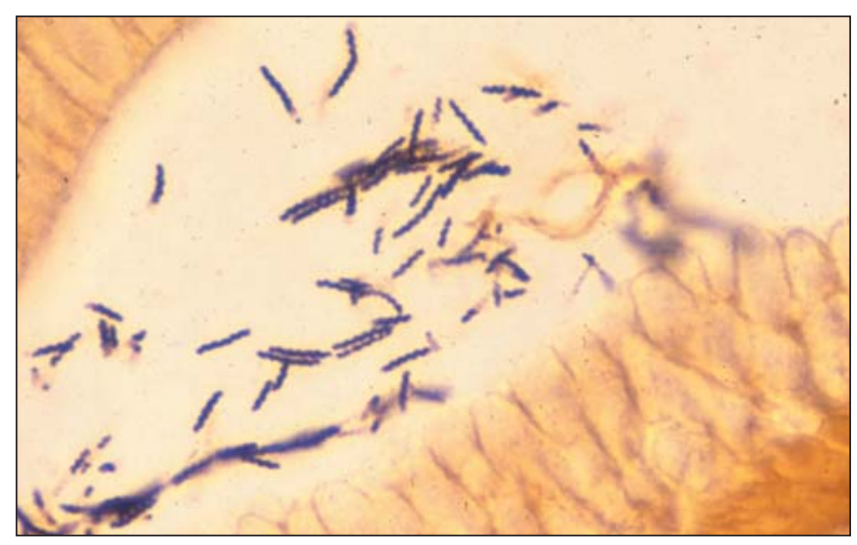

Figure 3) Corkscrew-like appearance of Helicobacter heilmannii (Warthin-Starry stain)

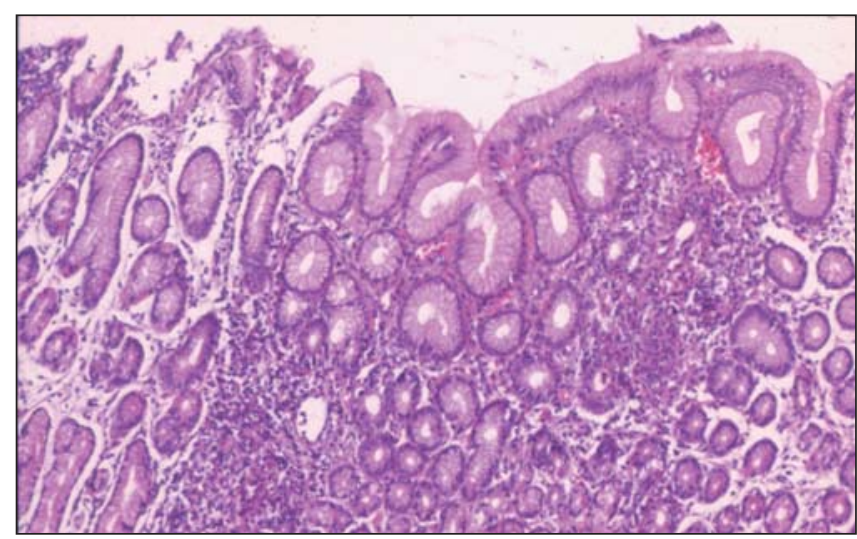

Figure 4) Crohn's gastritis: focal periglandular lymphocytic infiltrates

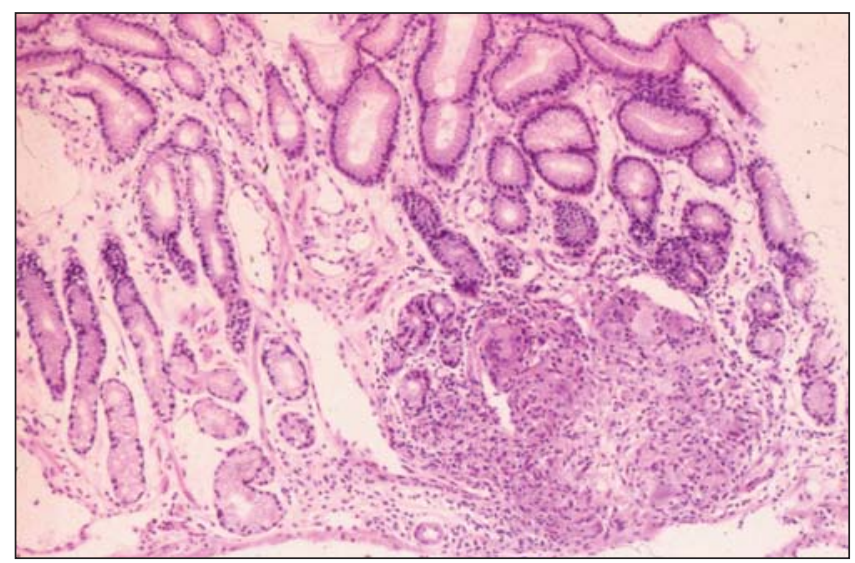

Figure 5) Crohn's gastritis: focal periglandular lymphocytic infiltration in combination with an epithelioid cell granuloma

account. Collagenous gastritis in collagenous colitis is extremely rare: among 924 patients with collagenous colitis, the authors investigated biopsies obtained from the stomachs of 340 patients and diagnosed collagenous gastritis in 18 patients (1.9\%) (unpublished data). 


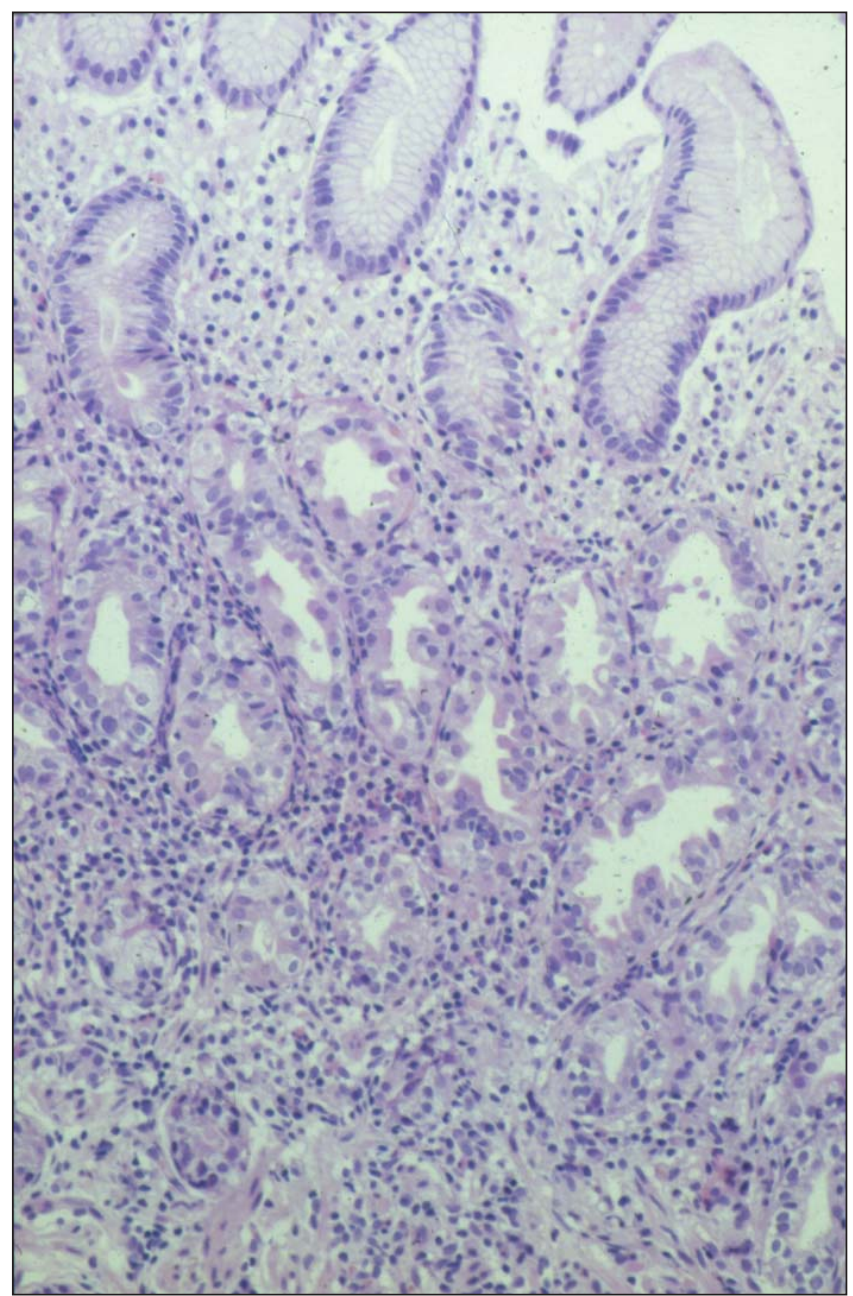

Figure 6) Active, nonatrophic autoimmune gastritis: diffuse periglandular lymphocytic infiltration with focal destruction of the corpus glands and hypertrophy of the parietal cells

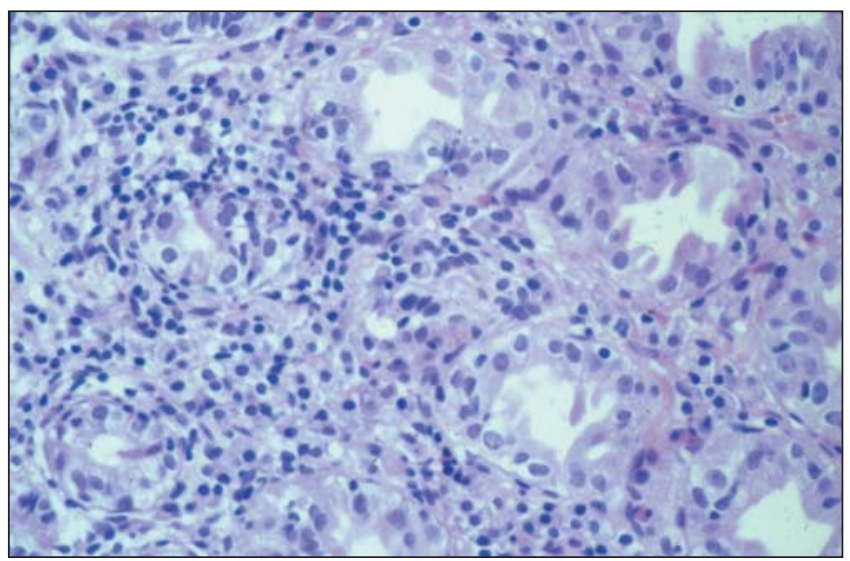

Figure 7) Active autoimmune gastritis; high magnification of the lymphocytic infiltration with focal destruction of the corpus glands and hypertrophy of the parietal cells

As with Crohn's gastritis, special forms of gastritis may also be masked by concurrent $H$ pylori gastritis. Persistent symptoms after eradication treatment for $\mathrm{H}$ pylori infection should, therefore, prompt a careful repeat endoscopy

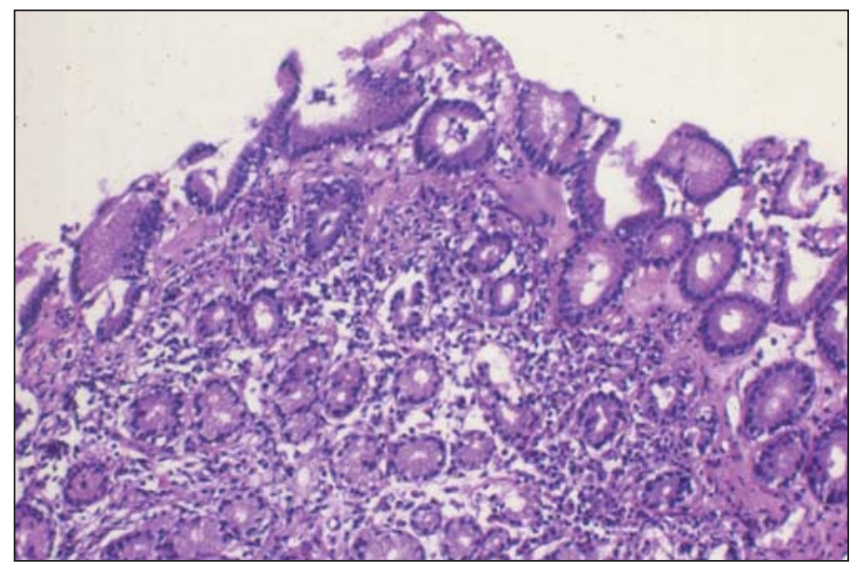

Figure 8) Collagenous gastritis in a patient with collagenous colitis: wide band of collagenous fibres beneath the surface epithelium

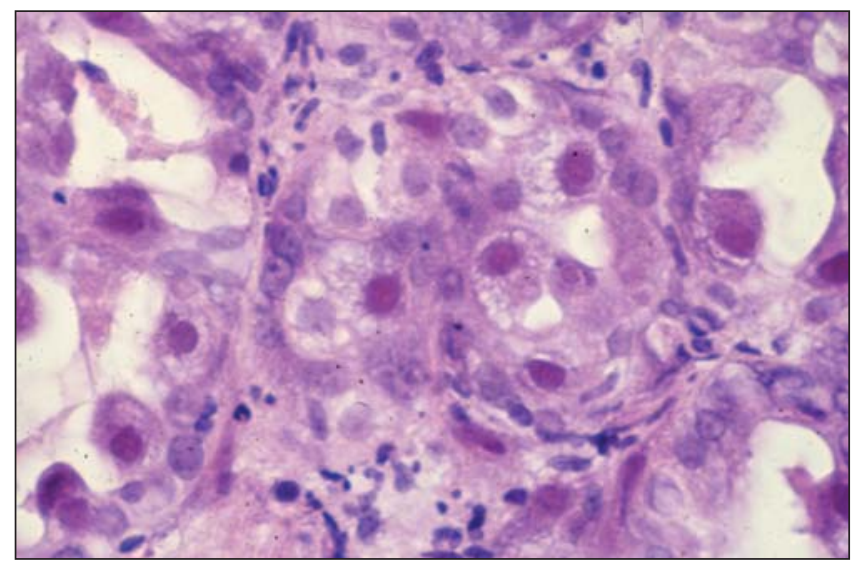

Figure 9) Cytomegalovirus gastritis with typical viral inclusion bodies in the epithelial nuclei

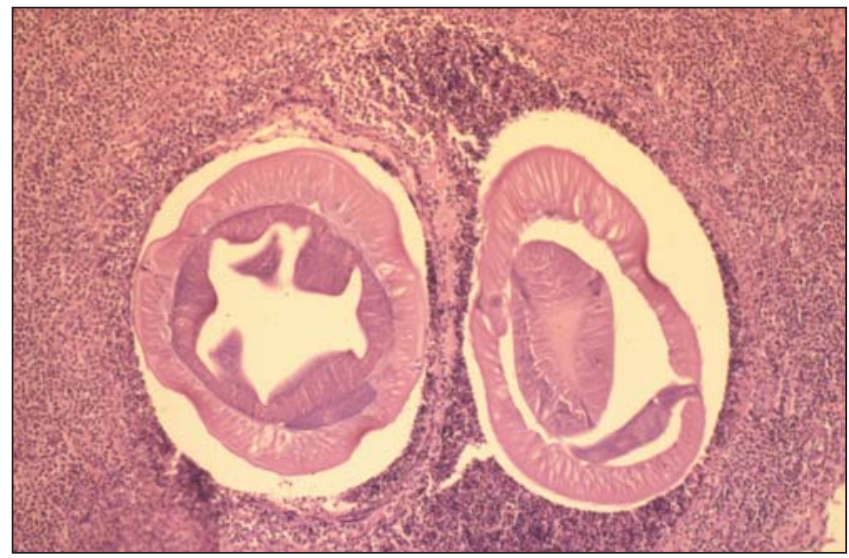

Figure 10) Eosinophilic gastritis induced by Anisakis marina

and biopsy examination, with the aim of searching for another rare form of gastritis as the cause of the patient's symptoms. In the case of eosinophilic gastritis, involvement of the small bowel and/or colon has to be excluded. 
In addition to an allergic genesis, medications containing acetylsalicylic acid may also act as possible triggers of eosinophil infiltration. For the differential diagnosis, the rare Churg-Strauss syndrome and, after ingestion of raw fish, anisakiasis must be taken into account. Another interesting form of gastritis is lymphocytic gastritis (27), which is defined as lymphocytic infiltration of the surface epithelium and foveolar epithelium with more than 25 intraepithelial lymphocytes per 100 epithelial cells (Figures 11 and 12). The endoscopic phenotype of lymphocytic gastritis is normal or mildly inflamed gastric mucosa (incidence in material obtained from 220 patients was approximately $75 \%$ ); gastritis varioliformis (multiple atypically localized chronic erosions in the corpus and fundus in the presence of normal antral mucosa) (20\%); and giant-fold gastritis (5\%). The third form, giant-fold gastritis, may mimic, endoscopically and clinically, Menetrier's disease with or without protein-losing syndrome. Most cases of giant-fold gastritis in the corpus and fundus are, however, presumably the result of an unusually pronounced reaction to $H$ pylori infection $(28,29)$, although the organism is detectable in only about $30 \%$ to $50 \%$ of such cases. A piece of evidence that supports this assumption is the high percentage of healing of lymphocytic gastritis by $H$ pylori eradication treatment in the authors' patients with and without evidence of $H$ pylori. Thus, in a group of 61 patients, regression of the lymphocytic gastritis following $H$ pylori eradication treatment was observed in $93.1 \%$ of the patients with histologically detectable $H$ pylori infection and in $84.3 \%$ of those with no such evidence of infection (unpublished data). Another possible cause of lymphocytic gastritis is celiac disease. In some of these patients, lymphocytic colitis is also present. On the basis of recent perceptions, the former descriptive diagnosis 'hypertrophic gastritis' or 'giantfold gastritis' should no longer be made. When endoscopy reveals hypertrophic rugae in the corpus, the pathologist should differentiate inflammation-related hypertrophic folds, that is, giant folds due to $H$ pylori infection $(28,29)$, cytomegalovirus infection and lymphocytic gastritis, from the noninflammatory diffuse foveolar hyperplasia (Menetrier's disease), glandular hyperplasia in the Zollinger-Ellison syndrome and neoplastic giant folds (gastric lymphoma or carcinoma). In extremely rare cases, giant folds may also be a result of extramedullary hemopoiesis in the gastric mucosa and superinfection of the stomach with Strongyloides species (unpublished data).

\section{H PYLORI-INDUCED FORMS OF GASTRITIS}

There is no doubt that $H$ pylori infection is responsible for the majority of cases of gastritis (6). In general, the inflammation induced by this infection is a chronic active gastritis, which means that both lymphocytes and neutrophils infiltrate the mucosa in a characteristic manner. In addition, apart from the inflammatory infiltrate, foci of intestinal metaplasia with resulting atrophy, lymphatic aggregates and lymphoid follicles occur, and the foveolar epithelium is replaced by regenerative epithelium with correspondingly reduced mucus secretion (30) (Figure 2, left). Because it can be found throughout the entire gastric mucosa from the pylorus up to the cardia, $H$ pylori should really be named 'Helicobacter ventriculi'. The result of its presence is a corresponding immune response within the entire stomach from cardia to pylorus - which can be identified histologically as gastritis. Thus, $\mathrm{H}$ pylori gastritis is always a pangastritis, although its severity may vary considerably between the antrum and corpus. One objective of the classification of $\mathrm{H}$ pylori gastritis is, on the basis of its grading and topographical pattern, to derive prognostic information that will allow one to use the diagnosis of gastritis to predict whether it is associated with an elevated risk of an $\mathrm{H}$ pylori-associated sequela. It is now becoming increasingly evident that, as a result of determining the topographic pattern of the grade and activity of the gastritis, intestinal metaplasia and focal atrophy, it is possible to subdivide $H$ pylori gastritis into a variety of different phenotypes.

Gastritis of the duodenal ulcer phenotype: If other rare causes of duodenal ulcers, such as Zollinger-Ellison syndrome or Crohn's disease, or the use of NSAIDs can be excluded, the ulcer is almost $100 \%$ certain to be a sequela of $H$ pylori gastritis (31). In the stomach of these patients, an antrum-dominant medium- to severe-grade gastritis can be found, while in the corpus, there is only mild inflammation (30-34). Foci of intestinal metaplasia and atrophy as a result of the gastritis in the antrum can be identified in the biopsy material of $20 \%$ of the patients; in contrast, the presence of these focal parameters in the corpus virtually excludes duodenal ulcer disease $(33,34)$. This pattern of gastritis is associated with a high level of acid secretion, which, in turn, is a significant factor in the pathogenesis of duodenal ulcer (31). Gastritis of the gastric cancer phenotype: The carcinoma phenotype of $H$ pylori gastritis is primarily characterized by MAG in the antrum and corpus (35-38). The atrophy may involve the entire stomach and may be associated with intestinal metaplasia; in some cases, such large areas may be involved that the histological search for $\mathrm{H}$ pylori in the biopsy material may be negative despite positive serology. A major characteristic of the infiltration with inflammatory cells is the typically severe corpus gastritis in these patients. Because this topography of the grade and activity of the gastritis frequently can be seen also in very early stages of carcinoma (39), these two diffuse parameters may be considered to precede the carcinoma. Furthermore, in studies of the gastritis found in first-degree relatives of patients with gastric cancer, Meining et al (40) were able to show that severe corpus gastritis is probably subject to hereditary influences, so that this gastritis phenotype is associated with the commonly described elevated familial risk of gastric carcinoma (41). Thus, the gastritis of the gastric cancer phenotype is, with regard to the pattern of the inflammatory infiltrate in the antrum related to the corpus, the 'reverse' of the duodenal ulcer phenotype (38). Presumably, these different phenotypes of $H$ pylori gastritis are caused by individual differences in the level of acid production (42). This 


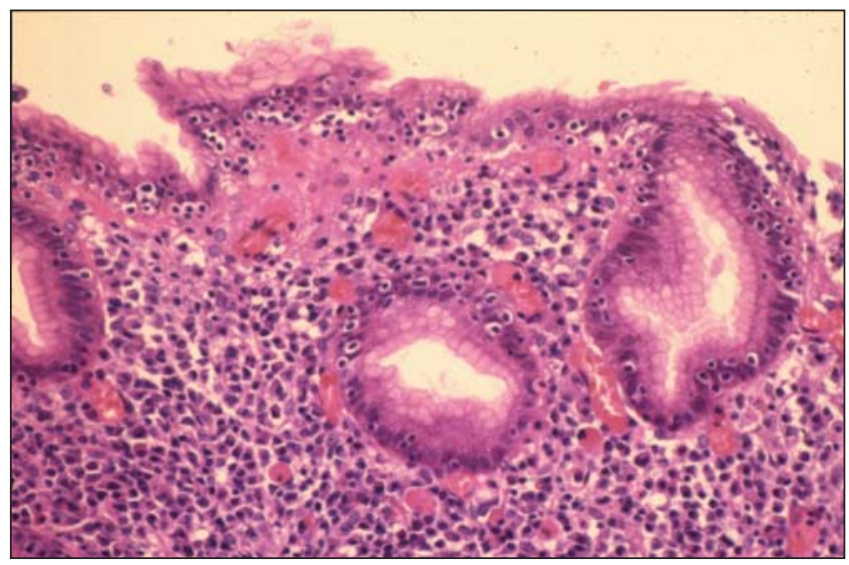

Figure 11) Lymphocytic gastritis: more than 25 intraepithelial lymphocytes per 100 epithelial cells

observation is also reflected in the fact that a history of duodenal ulcer disease is a protective factor against the development of gastric cancer (43). Of importance for the daily routine is, of course, the question of whether effective prevention of gastric carcinoma can be achieved by the eradication of $\mathrm{H}$ pylori. In an attempt to find an answer to this question, a number of studies with different approaches are currently being conducted worldwide. Because the results have not yet been published, however, no definitive answer to the question can be given (44). In view of what is currently known about the pattern and distribution of gastritis in terms of its role in carcinogenesis, however, we hold the opinion that, as a carcinoma preventive measure, an attempt can and should be made, in patients with gastritis of the carcinoma phenotype, to treat the $H$ pylori infection. In Germany, Austria and the Czech Republic, a prospective study is currently being conducted to investigate this possibility (45). Initial results are expected in about five years time. In patients with a familial history of gastric cancer, however, $H$ pylori eradication treatment should always be given, irrespective of the phenotype of the gastritis.

\section{DOES THE CLASSIFICATION AND GRADING OF GASTRITIS MAKE GOOD SENSE?}

In the 1970s and 1980s, many pathologists evaluating gastritis merely diagnosed 'some inflammatory changes, no cancer', while others were content with such descriptive diagnoses as 'superficial gastritis' or 'atrophic gastritis'. The renaissance into research of gastritis triggered by the rediscovery of $H$ pylori resulted in considerable advances in this apparently insignificant area of histopathological gastritis diagnosis. Numerous 'new' forms of gastritis such as chemically induced reactive gastritis, $H$ heilmannii gastritis, lymphocytic gastritis and its subtypes, Crohn's gastritis and collagenous gastritis, have since been identified. Also, the former diagnosis of 'hypertrophic gastritis' has become more differentiated, so that some forms can now be cured by specific therapies. Today, autoimmune gastritis of the corpus mucosa can be diagnosed in early stages before complete atrophy of the parietal cells has occurred. In the etiopatho-

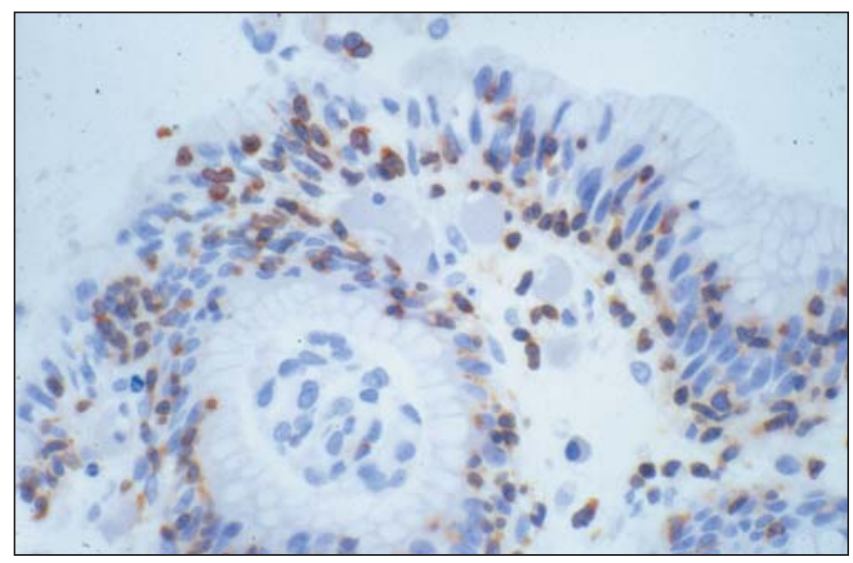

Figure 12) Lymphocytic gastritis immunohistochemistry: CD3-positive intraepithelial lymphocytes

genesis of A gastritis, recent evidence points to the possibility of there being at least two and perhaps three types of $\mathrm{A}$ gastritis: gastritis induced by parietal cell antibodies; gastritis induced by $\mathrm{H}$ pylori; and, possibly, a mixed form with both parietal cell antibodies and $H$ pylori antibodies.

On the basis of this new perception, the signs are that $\mathrm{H}$ pylori-induced A gastritis may be cured by eradicating the $H$ pylori. A problem that has yet to be resolved is whether the question 'Is H pylori gastritis present?' should not simply be answered 'yes' or 'no', and whether grading of the gastritis parameters should be forgone. On the basis of such grading, however, indirect conclusions can be drawn as to the pathogenicity of the organism, because highly pathogenic cagA-positive Helicobacter species strains induce a more severe and more highly active gastritis than cagA-negative strains. Further, it appears that a comparative grading of the gastritis parameters in the corpus and antrum may, in the future, permit the identification of high risk gastritis such as gastritis of the duodenal ulcer phenotype and gastritis of the carcinoma phenotype. It can thus be seen that classification and grading of the inflammatory processes of the gastric mucosa, in accordance with the updated Sydney system, are indispensable and should be accepted worldwide as the gold standard of the histopathological workup of gastritis.

\section{CONCLUSIONS}

The Sydney system led to the revival of gastritis research, the classification of new forms of gastritis, and the discovery of new facts about the etiopathogenesis of the various forms of gastritis and their treatment. The updated Sydney system is a further development with advantages of its own. However, the grading of atrophy is a problem that still awaits resolution. With regard to the etiopathogenesis of gastritis, however, good agreement has been achieved. Approximately $90 \%$ of all forms of gastritis can now be classified on an etiopathogenic basis. As a result, there are new indications for further diagnostic investigations and treatment. The updated Sydney system is not the last word, but is open to the discovery of new facts - for example, in $\mathrm{H}$ pylori-induced autoimmune gastritis and Crohn's gastritis. 


\section{REFERENCES}

1. Marshall BJ, Royce H, Annear DI, et al. Original isolation of Campylobacter pyloridis from human gastric mucosa. FEMS Microbiol Lett 1994;25:83-8.

2. Price AB. The Sydney system: histological division. J Gastroenterol Hepatol 1991;6:209-22.

3. Wyatt JI, Dixon MF. Chronic gastritis - a pathogenetic approach. J Pathol 1988;154:113-24.

4. Stolte M, Heilmann KL. Neue Klassifikation und Graduierung der Gastritis. Leber Magen Darm 1989;19:220-6.

5. Correa P, Yardley M. Grading and classification of chronic gastritis: one American response to the Sydney System. Gastroenterology 1992;102:355-9.

6. Dixon MF, Genta RM, Yardley JH, Correa P and the Participants in the International Workshop on the Histopathology of Gastritis, Classification and Grading of Gastritis. The updated Sydney System. Am J Surg Pathol 1996;20:1161-81.

7. El-Zimaity HM, Graham DY, al-Assi MT, Genta RM. Interobserver variation in the histopathological assessment of Helicobacter pylori gastritis. Hum Pathol 1996;27:35-41.

8. Sobala GM, King RF, Axon AT, Dixon MF. Reflux gastritis in the intact stomach. J Clin Pathol 1990;43:303-6.

9. Valle J, Seppälä K, Sipponen P, Kosunen T. Disappearance of gastritis after eradication of Helicobacter pylori. A morphometric study. Scand J Gastroenterol 1991;26:1057-65.

10. Stolte M, Eidt S. Lymphoid follicles in antral mucosa: immune response to Campylobacter pylori? J Clin Pathol 1989;42:1269-71.

11. Stolte M, Wellens E, Bethke B, Ritter M, Eidt H. Helicobacter heilmannii (formerly Gastrospirillum hominis) gastritis: an infection transmitted by animals? Scand J Gastroenterol 1994;29:1061-4.

12. Solnick JV, O'Rourke J, Lee A, Paster BJ, Dewhirst FE, Tomkins LS. An uncultured gastric spiral organism is a newly identified Helicobacter in humans. J Infect Dis 1993;168:379-85.

13. Stolte M, Kroher G, Meining A, Morgner A, Bayerdörffer E, Bethke B. A comparison of Helicobacter pylori and Helicobacter heilmannii gastritis. A matched control study involving 404 patients. Scand J Gastroenterol 1997;32:28-33.

14. Meining A, Kroher G, Stolte M. Animal reservoirs in the transmission of Helicobacter heilmannii: results of a questionnaire-based study. Scand J Gastroenterol 1998;33:795-8.

15. Dieterich C, Wiesel P, Neiger R, Blum AL, Corthesy-Theulaz IE. Presence of multiple Helicobacter heilmannii strains in an individual suffering from ulcers and in his two cats. J Clin Microbiol 1998;36:1366-70.

16. Leena EH, Sipponen PI, Smitten KAJ. Involvement of gastroduodenal mucosa in Crohn's disease. Eur J Gastroenterol Hepatol 1992;4:23-8.

17. Meining A, Bayerdörffer E, Bästlein E, et al. Focal inflammatory infiltrations in gastric biopsy specimens are suggestive of Crohn's disease. Scand J Gastroenterol 1997;32:229-37.

18. Oberhuber G, Püspök A, Östereicher C, et al. Crohn's disease of the stomach is histologically characterized by focal active gastritis. Gastroenterology 1997;112:698-706.

19. Wright CL, Ridell RH. Histology of the duodenum and stomach in Crohn's disease. Mod Pathol 1996;9:68A. (Abst)

20. Halme L, Kärkkäinen P, Rautelin H, Kosunen TU, Sipponen P. High frequency of helicobacter negative gastritis in patients with Crohn's disease. Gut 1996;38:379-83.

21. Herz R, Schaube J, Meining A, Stolte M. Gastritis associated with Crohn's disease can be masked by Helicobacter pylori gastritis. Scand J Gastroenterol 1999;34:471-3.

22. Strickland RG, Mackay IR. A reappraisal of the nature and significance of chronic atrophic gastritis. Dig Dis 1973;18:426-40.

23. Faller G, Steininger H, Eck M, Hensen J, Hahn EG, Kirchner T. Antigastric autoantibodies in Helicobacter pylori gastritis: prevalence, in-situ binding sites and clues for clinical relevance. Virchows Arch 1996;427:483-6.
24. Negrini R, Savio A, Poiesi C, et al. Antigenic mimicry between Helicobacter pylori and gastric mucosa in the pathogenesis of body atrophic gastritis. Gastroenterology 1996;111:655-65.

25. Stolte M, Meining A, Koop H, Seifert E. Eradication of Helicobacter pylori heals atrophic corpus gastritis caused by long-term treatment with omeprazole. Virchows Arch 1999;434:91-4.

26. Stolte M, Meier E, Meining A. Cure of autoimmune gastritis by Helicobacter pylori eradication in a 21-year-old male. Z Gastroenterol 1998;36:571-3.

27. Hoat J, Hamichi L, Wallez L, Mainguet P, Lambert R. Lymphocytic gastritis: a newly described entity: a retrospective endoscopic and histological study. Gut 1988;29:1258-64.

28. Stolte M, Bätz Ch, Eidt S. Giant fold gastritis - a special form of Helicobacter pylori associated gastritis. Z Gastroenterol 1993;31:745-6.

29. Stolte M, Bätz Ch, Bayerdörffer E, Eidt S. Helicobacter pylori eradication in the treatment and differential diagnosis of giant folds in the corpus and fundus of the stomach. Z Gastroenterol 1995;33:198-201.

30. Stolte M, Stadelmann O, Bethke B, Burkhard G. Relationship between the degree of Helicobacter pylori colonisation and the degree and activity of gastritis, surface epithelial degeneration and mucus secretion. Z Gastroenterol 1995;33:89-93.

31. Walker MM, Dixon MF. Gastric metaplasia: its role in duodenal ulceration. Aliment Pharmacol Ther 1996;10(Suppl 1):119-28.

32. Solcia E, Villani L, Fiocca R, et al. Effects of eradication of Helicobacter pylori on gastritis in duodenal ulcer patients. Scand J Gastroenterol 1994;29(Suppl 201):28-34.

33. Khulusi S, Mendall MA, Patel P, Levy J, Badve S, Northfield TC. Helicobacter pylori infection density and gastric inflammation in duodenal ulcer and non-ulcer subjects. Gut 1995;37:319-24.

34. Meining A, Stolte M, Hatz R, et al. Differing grade and distribution of gastritis in Helicobacter pylori associated diseases. Virchows Arch 1997;431:11-5.

35. Sipponen P, Kekki M, Seppälä K, Siurala M. The relationship between chronic gastritis and gastric acid secretion. Aliment Pharmacol Ther 1996;10(Suppl 1):103-18.

36. Sipponen P, Kekki M, Haapakoski J, Ihamäki T, Siurala M. Gastric cancer risk in chronic atrophic gastritis: statistical calculations of cross-sectional data. Int J Cancer 1985;35:173-7.

37. Correa P. A human model of gastric carcinogenesis. Cancer Res 1988;48:3554-60.

38. Sipponen P, Stolte M. Clinical impacts of routine antral and corpus biopsies. Endoscopy 1997;29:671-8.

39. Meining A, Bayerdörffer E, Müller P, et al. Gastric carcinoma risk index in patients infected with Helicobacter pylori. Virchows Arch 1998;432:311-4.

40. Meining A, Hackelsberger A, Daenecke C, Stolte M, Bayerdörffer E, Ochsenkühn T. Increased cell proliferation of the gastric mucosa in first degree relatives of gastric carcinoma patients. Cancer 1998;83:876-81.

41. Zanghieri G, Di Gregorio C, Sacchetti C, et al. Familial occurrence of gastric cancer in the 2-year experience of a population-based registry. Cancer 1990;66:2047-51.

42. Lee A, Dixon MF, Danon SJ, et al. Local acid production and Helicobacter pylori: a unifying hypothesis of gastroduodenal disease. Eur J Gastroenterol Hepatol 1995:7:461-5.

43. Hansson LE, Nyren O, Hesing AW, et al. The risk of stomach cancer in patients with gastric or duodenal ulcer disease. $\mathrm{N}$ Engl J Med 1996;335:242-9.

44. Forman D. Lessons from ongoing intervention studies. In: RH Hunt, GNJ Tytgat, eds. Helicobacter pylori: basic mechanisms to clinical care. Dordrecht: Kluwer Academic Publishers, 1998:354-60.

45. Stolte M, Bayerdörffer E, Miehlke S, et al. Helicobacter pylori Eradikation zur Prophylaxe des Magenkarzinoms? Einladung zur deutsch-österreichischen PRISMA-Studie. Leber Magen Darm 1998;28:128-35. 


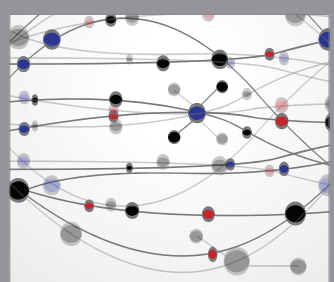

The Scientific World Journal
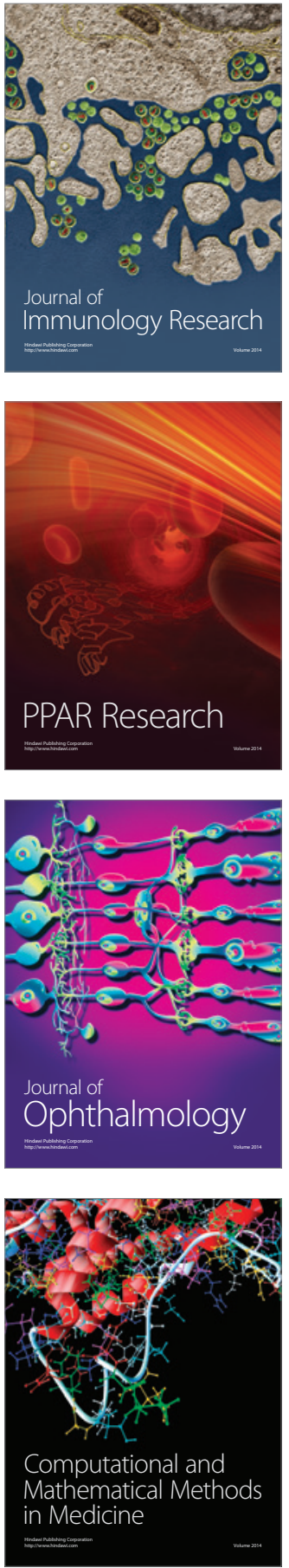

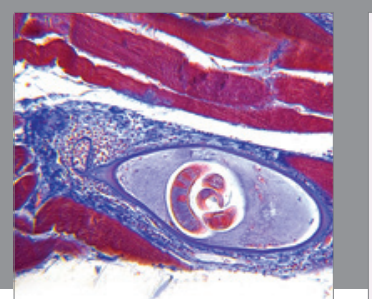

Gastroenterology Research and Practice

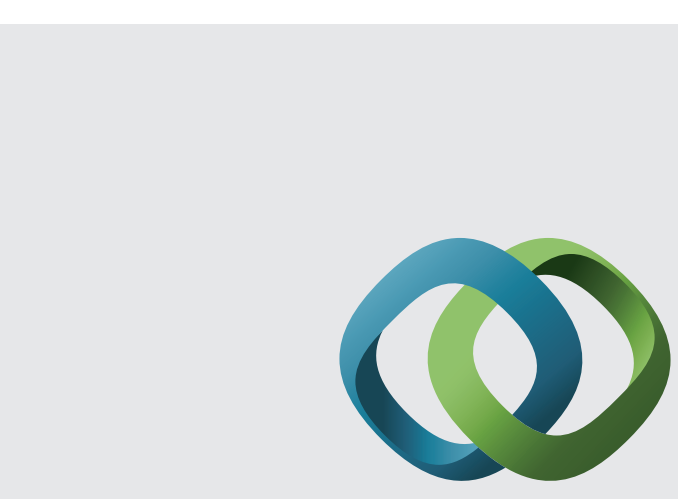

\section{Hindawi}

Submit your manuscripts at

http://www.hindawi.com
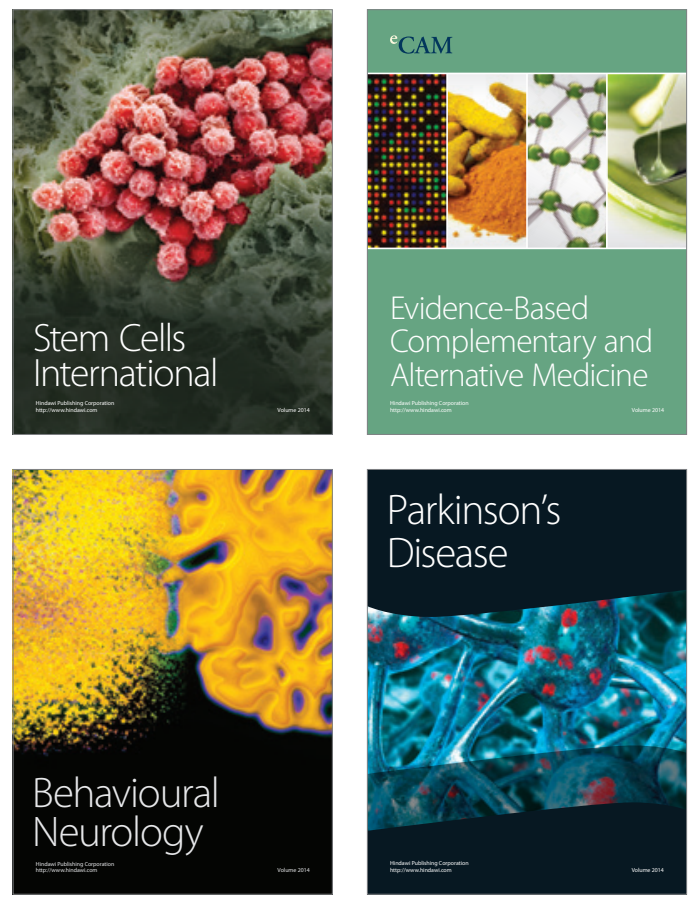
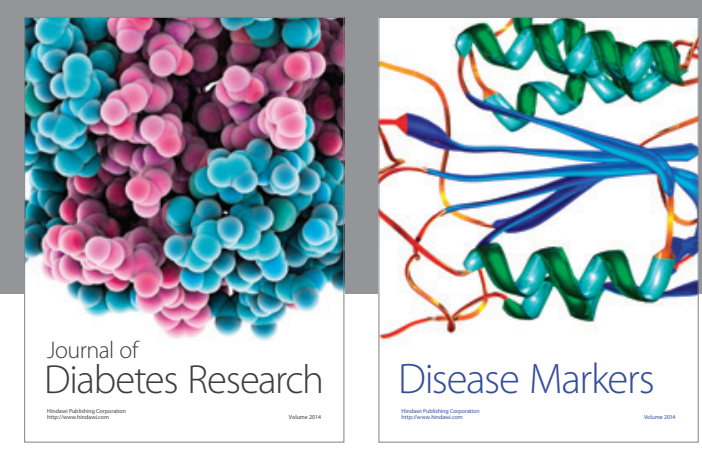

Disease Markers
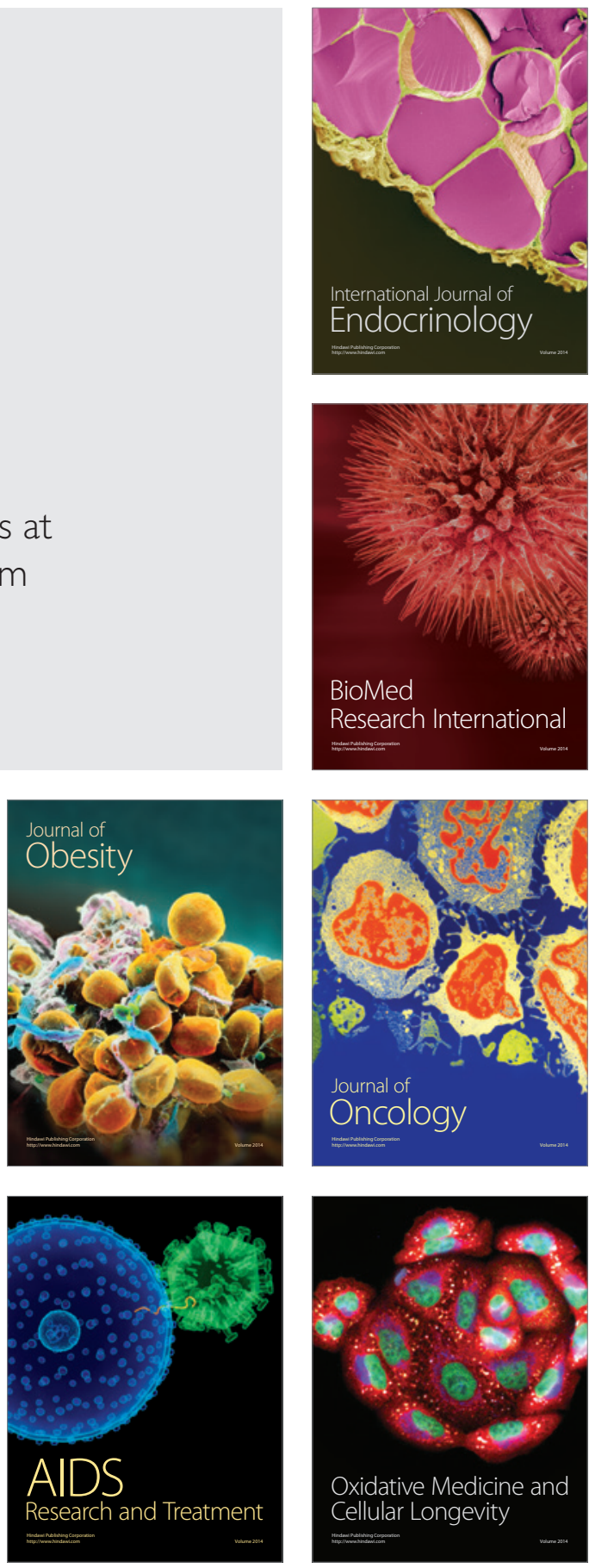